\title{
Enhancement of WiMAX networks using OPNET modeler platform
}

\author{
Noor Nateq Alfaisaly ${ }^{1}$, Suhad Qasim Naeem ${ }^{2}$, Azhar Hussein Neama ${ }^{3}$ \\ ${ }^{1}$ Department of computer networks Engineering, Al Nahrain University, Iraq \\ ${ }^{2,3}$ Department of information and communication Engineering, Al Nahrain University, Iraq \\ ${ }^{1-3}$ College of Information Engineering, Al Nahrain University, Iraq
}

\begin{tabular}{l} 
Article Info \\
\hline Article history: \\
Received Dec 12, 2020 \\
Revised Jun 18, 2021 \\
Accepted Aug 4, 2021 \\
\hline
\end{tabular}

\section{Keywords:}

Internet protocol

MOS

OPNET 14.5

Voice over Internet protocol Worldwide interoperability for microwave access

\begin{abstract}
Worldwide interoperability microwave access (WiMAX) is an 802.16 wireless standard that delivers high speed, provides a data rate of $100 \mathrm{Mbps}$ and a coverage area of $50 \mathrm{~km}$. Voice over internet protocol (VoIP) is flexible and offers low-cost telephony for clients over IP. However, there are still many challenges that must be addressed to provide a stable and good quality voice connection over the internet. The performance of various parameters such as multipath channel model and bandwidth over the Star trajectoryWiMAX network were evaluated under a scenario consisting of four cells. Each cell contains one mobile and one base station. Network performance metrics such as throughput and MOS were used to evaluate the best performance of VoIP codecs. Performance was analyzed via OPNET program14.5. The result use of multipath channel model (disable) was better than using the model (ITU pedestrian A). The value of the throughput at $15 \mathrm{~dB}$ was approximately 1600 packet/sec, and at $-1 \mathrm{~dB}$ was its value 1300 packet/se. According to data, the Multipath channel model of the disable type the value of the MOS was better than the ITU Pedestrian A type.
\end{abstract}

This is an open access article under the CC BY-SA license.

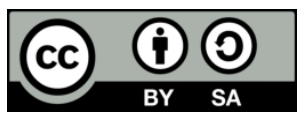

\section{Corresponding Author:}

Noor Nateq Fadhil

Department of computer networks Engineering

Al Nahrain University, Iraq

Email: noornateq_2014@yahoo.com

\section{INTRODUCTION}

A wireless LAN (WLAN) is a data transmission system designed to provide location-independent network access between computing devices by using radio waves rather than a cable infrastructure. The 802.11 specification as a standard for wireless LANS was ratified by the institute of electrical and electronics engineers (IEEE) in the year 1997. This version of 802.11 provides for $1 \mathrm{Mbps}$ and $2 \mathrm{Mbps}$ data rates and a set of fundamental signaling methods and other services. Like all IEEE 802 standards, the 802.11 standards focus on the bottom two levels the ISO model, the physical layer and link layer [1].

The way people communicate was changed via VoIP applications like FaceTime, Google Talk, and Skype. Because it is inexpensive, VoIP is a vital alternate to costly conventional public switched telephone network (PSTN). VoIP parameters are defining its QoS like throughput, jitter, end to end delay, and mean opinion score (MOS) [2].

The current WiMAX and WiFi wireless networks offer flexibility for supporting real-time applications like VoIP [3]. Also, the technology of IEEE 802.11 (WiFi) is beneficial as low-cost wireless Internet access, whereas IEEE802.16 (Wi-MAX) is providing high data rates (up to $75 \mathrm{Mbps}$ ) and a large coverage area (about $50 \mathrm{~km}$ ) utilizing radio links [4]. In this paper, the performance of various parameters such as multipath channel model and bandwidth over the Star trajectory WiMAX network will be evaluated 
under a scenario consisting of four cells. Many researchers study a WIMAX as Rajaraman [5] presented WIMAX use of a spiral resonator. The conventional patch antenna resonates at a frequency of $2.785 \mathrm{GHz}$ while the modified antenna resonates at two frequencies of $2.45,2.57 \mathrm{GHz}$ with a gain of $4.19,4.59 \mathrm{~dB}$ respectively. The percentage of miniaturisation is found to be $30.2 \%, 17.9 \%$ in the two chosen spectras. As well as Singh [6] presented WIMAXperformance investigation of the WIMAX system under different applications generating high load data traffic, various modulation schemes like BPSK, QPSK and QAM 64. The aim of this paper is prposed evaluation performance of various parameters such as multipath channel model and bandwidth over the Star trajectoryWiMAX network were evaluated under a scenario consisting of four cells. Each cell contains one mobile and one base station. Network performance metrics such as throughput and MOS were used to evaluate the best performance of VoIP codecs.

\section{RELATED WORKS}

\subsection{VOIP}

VoIP is specified as one of the internet technologies used to transmit multimedia and voice-over IPbased networks, particularly the Internet [7], [8]. VoIP is majorly utilized as one of the communication protocols for replacing conventional telephone technologies, PSTN. Recently, the popularity of VoIP was increased because it is inexpensive compared to traditional long-distance telephone calls. In addition, the telephone calls might be made over computer networks, like the Internet, with VoIP-to-VoIP at no additional cost other than the monthly fee the user is paying for Internet access.

VoIP is converting the analog voice signals into digital data packets from an end-user. The restored data packets will be transmitted to another end-user via a computer network. The digital data packets will undergo conversion again and will end up being the original analog voice signal. This technology provides service for real-time transmission of conversations with cost-effectiveness and flexibility. VoIP-to-PSTN services are also available at a fixed monthly payment; however, this type of service's performance is beyond the scope of this project and will not be discussed or analyzed. There are also some downsides to VoIP technology. It has an average drop of calls at 3\%, and it could go up to 5\%, while regular phone services have a moderate decrease in calls at less than $0.1 \%$. In case of a power outage or lost access to the Internet, VoIP calls would not be able to make. Furthermore, there are no available VoIP-to-VoIP calls for emergency services.

\subsection{VOIP over WI-MAX}

One alternative solution to wired networks is Wi-MAX as a broadband wireless technology; it provides a data rate of $75 \mathrm{Mbps}$ with $50 \mathrm{~km}$ as coverage area [4]. In addition, it is supporting the requirements of QoS via many applications, particularly real-time applications like VoIP. There are four different traffic classes used by Wi-MAX for supporting its applications:

a) Best effort (BE) was developed for web browsing applications [9] that don't need QoS.

b) Non-real time polling service (nrtPS) supports non-real-time applications like FTP [10] requiring variable data sizes.

c) Unsolicited grant services (UGSs) are supporting the applications of constant bit rate (CBR) like VoIP with no silence suppression [10], [11], in which users are assigned a fixed bandwidth via base station (BS).

d) Real-time polling service (rtPS) is supporting the real-time applications with data of variable sizes like MPEG [11], in which Bandwidth is allocated via BS based on the request regarding subscriber station (SS).

Even though that Wi-MAX was developed for providing broadband Internet service, the applications of VoIP have an increased effect on the performance related to Wi-MAX networks [12].

\subsection{VOIP application QoS}

Currently, users benefit from present networks of data via video calls, voice calls, and text messages. Conventional phone networks cannot compete with such service types because of their reduced operating and equipment costs and the capability of integrating data and voice applications [13]. Also, QoS for VoIP was evaluated via performance metrics like jitter, end to end delay, and Mean Opinion Score MOS.

a) The scale of MOS is varying between 1 and 5, also measuring the voice quality. Furthermore, the value related to the most inferior quality was 1 , while the optimal quality was 5 [14], as can be seen from Table1. 


\begin{tabular}{lcl} 
& Table & 1. MOS [15] \\
\hline Scale of Quality & Score & \multicolumn{1}{c}{ The scale of Listening Effort } \\
\hline Excellent & 5 & No efforts needed \\
Good & 4 & No considerable efforts needed \\
Fair & 3 & Moderate efforts needed \\
Poor & 2 & Substantial efforts needed \\
Bad & 1 & No meaning understood with efforts \\
\hline
\end{tabular}

b) Jitter can be defined as the arrival time variation related to consecutive packets [16]. Before the decoding, the packages arrived at limited size buffers and a few packages might come out of order or be lost. Jitter was calculated by evaluating the differences in packets delay overtime period [14].

c) Packet's end-to-end delays were evaluated via the speakers' calculation of delays from the speakers to the receivers. Also, it involves decoding and encoding delay, network delay, decompression, and compression delays [16].

The telecommunication standardization sector of the international is providing the guidelines for voice quality measurements for jitter and end-to-end delay, as can be seen in Table 2. Tele-communications union (ITU-T) [16]. A voice call of better quality might be having a delay in the range of (0ms-150ms), while the jitter in range of $(0-20) \mathrm{ms}$. Yet, when a call is experiencing a delay over $300 \mathrm{~ms}$ or jitter over $50 \mathrm{~ms}$, it will be specified as poor quality, or else, calls specified to be of suitable quality.

Table2. Guidelines for the quality of voice [16].

\begin{tabular}{ccc}
\hline Network parameters & Good & Acceptable \\
\hline Delays (ms) & $0 \_150$ & $150-300$ \\
Jitters (ms) & $0 \_20$ & $20-50$ \\
\hline
\end{tabular}

\subsection{Codecs of VOIP}

VoIP depends on many codecs utilized to compress and decompress the audio samples; each of the codecs is applying a unique algorithm. Table 3 is providing a list of significant codecs [15]. This study is evaluating 3 VoIP codecs: G711, G723, and G729.

Table3. Major codecs of VoIP [12].

\begin{tabular}{ccc}
\hline Codec & Data rates $(\mathrm{kb} / \mathrm{s})$ & MOS scores \\
\hline G. 711 & 64 & 4.30 \\
G. 723 & 5.30 & 3.60 \\
G. 726 & 32 & 4.00 \\
G. 728 & 16 & 3.90 \\
G. 729 & 8 & 4.00 \\
\hline
\end{tabular}

\subsubsection{G. 711}

This is one of the public domain codecs majorly utilized in the applications of VoIP. In 1972, it was developed via ITU. In addition, it applies a logarithmic compression, which is compressing each one of the 16-bit samples to 8 bits. Therefore, its bit rate was $64 \mathrm{kbps}$, specified as the maximum bit rate between codecs. Furthermore, G. 711 offers an excellent quality of audio, and the value of MOS was 4.3 [17].

\subsubsection{G. 723}

This is considered one of the licensed codecs; it was developed for calls across modem links with (28.8kbps and 33kbps) data rates. Thus, it has two types with different bit rates: 6.4 and 5.3kbps [14]. This work considers $5.3 \mathrm{kbps}$, which is based on algebraic code excited linear prediction (ACELP), while the value of MOS was 3.60 [17].

\subsubsection{G729}

This has been considered one of the licensed codecs developed to deliver excellent quality of calls without high-bandwidth consumption [17]. It has been developed based on the conjugate structure ACELP (CS-ACELP) algorithm with an (8kbps) bit rate, while the values of MOS value were 4.0 [17], [18].

Recently, there was a rapid development in many wireless technologies. Thus, there was an increase in the requirements for wireless data services and multimedia applications like video streaming and VoIP [19]. 
Also, VoIP and video streaming were increasingly significant, particularly following the use of Wi-MAX networks in various nations [20]. Furthermore, studies tackled many features of VoIP over Wi-MAX. Besides, the researchers in [14] examined the performance related to VoIP as well as video streaming over Wi-MAX network (IEEE 802.16d for a fixed, nomadic user and IEEE 802.16e for mobile user)., and utilizing bandwidth (10 and $20 \mathrm{MHz}$ ). The results showed excellent performance in the case when using more channel bandwidth, while the packet loss was perfect in the case when utilizing IEEE 802.16e. There have been 8-users served when operating $10 \mathrm{MHz}$ as channel bandwidth and 16-users when using $20 \mathrm{MHz}$ as channel bandwidth. A study conducted by [21] examined the data and voice support in the Wi-MAX network. Their study's goal has been to read QoS's deployment over Wi-MAX network, also comparing the performance acquired utilizing two distinctive Wi-MAX service classes, for instance, ertPS and UGS. A study conducted by [22] examined a fixed Wi-MAX network for evaluating the VoIP performance. The presented work is evaluating the performance of VOIP related to Wi-MAX network with using various bandwidths and indicating the impact of differences in the multipath channel model on results, along with using Wi-MAX service class UGS. The service class of UGS has the best performance parameters serving VoIP.

\section{RESEARCH METHOD}

This paper has a Scenario consists of four cells, and each cell contains one mobile and one base station. Work through it to evaluate the performance of VOIP over the WiMax network by using OPNET MODELER 14.5. With change some parameters to get the best results. In Figures 1-4 clarify the parameters for each of them in Figure 1 WiMAX configureuration including the numbers of rows and efficiency mode (mobility and ranging enabled) the reason for choosing this type is because the project includes a mobile node. Wimax configure. Contents scheduling type (UGS) chose this type because it is used with VOIP. There are other types, for example (steps it is used with the active voice detection technology, rtps with video, nrtps with FTP and HTTP, best effort but this type does not have any guarantees. Moreover, OFDM PHYprofiles (wireless OFDM 20MHz), in Figure 2 also application configureurations (node-0) includes the description (voice PCM Quality speech) this type it has a high quality of voice, in Figure 3 profile configureuration. (node-1) includes many rows and profile name (voice_app) because I reported about VOIP. Figure 4 WiMAX base station (BS) the WiMAX parameter antenna gain $15 \mathrm{~dB}$ and in Figure 5 and 6 mobiles (4-1) (1-1) have these mobiles the same Path loss parameter (free space). However, different int the multipath channel model in mobile (4-1) (disabled) and the mobiles [(1-1), (2-1), (3-1)] the multipath channel model (ITU Pedestrian A).

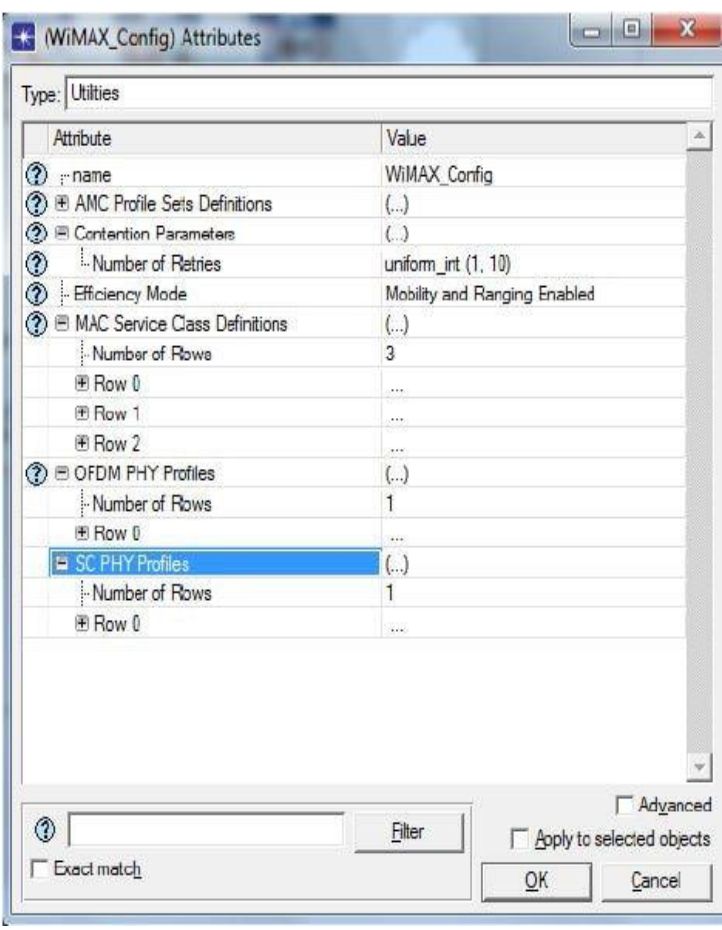

Figure 1. Wimax configureuration

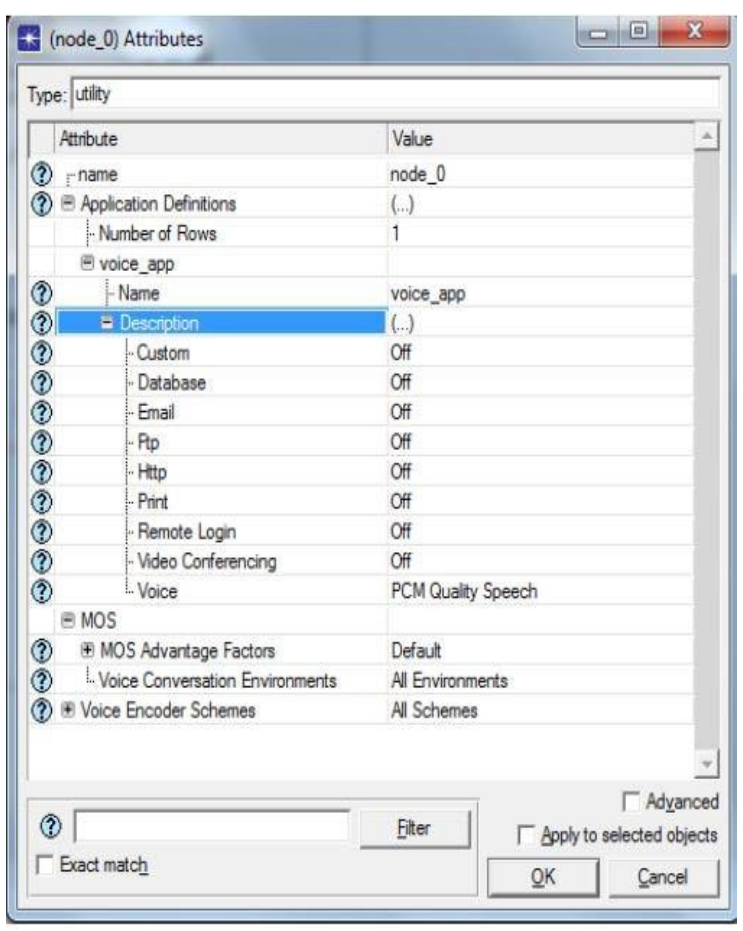

Figure 2. Application configureuration 


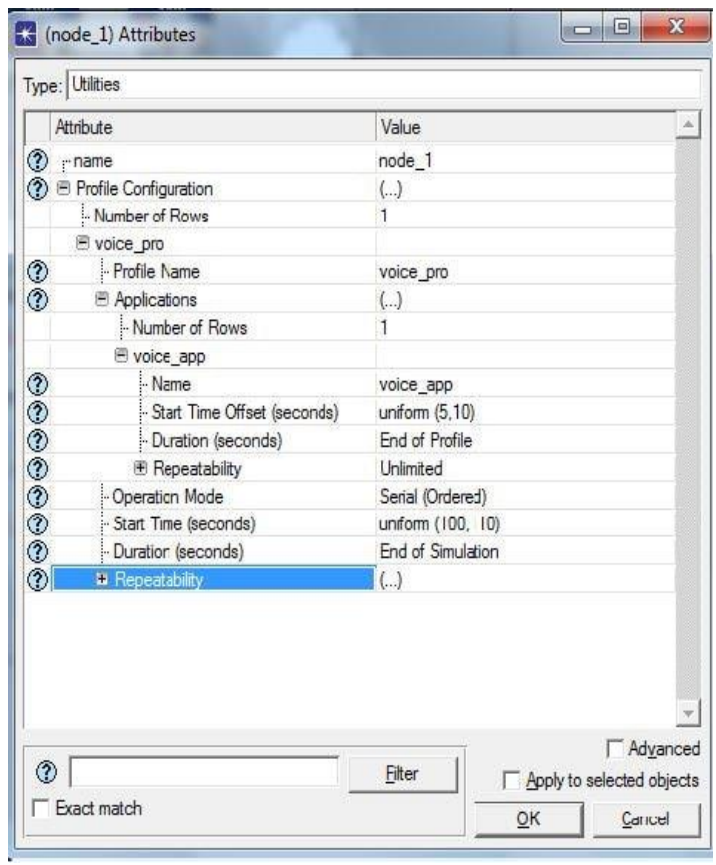

Figure 3. Profile configureuration

\begin{tabular}{|c|c|c|c|c|}
\hline \multicolumn{2}{|c|}{ * (Mobile_4_1) Attributes } & \multicolumn{3}{|c|}{0 回 $x$} \\
\hline \multicolumn{5}{|c|}{ Type:|workstation } \\
\hline \multicolumn{2}{|c|}{ Attribute } & \multicolumn{2}{|l|}{ Value } & $\Delta$ \\
\hline (2) & PHY Profile & \multicolumn{2}{|c|}{ WirelessOFDMA $20 \mathrm{MHz}$} & \\
\hline (?) & PHY Profile Type & \multicolumn{2}{|c|}{ OFDM } & \\
\hline & E SS Parameters & \multicolumn{2}{|l|}{ (..) } & \\
\hline (2) & BS MAC Address & \multicolumn{2}{|c|}{ Distance Based } & \\
\hline (?) & ¡ Downlink Service Fows & \multicolumn{2}{|c|}{ (..) } & \\
\hline (3) & $Ð$ Uplink Service Flows & \multicolumn{2}{|l|}{ (..) } & \\
\hline \multirow[t]{2}{*}{ (3) } & Multipath Channel Model & \multicolumn{2}{|l|}{ Disabled } & \\
\hline & ๑) Pathloss Parameters & \multicolumn{2}{|l|}{ Free Space } & \\
\hline (2) & Ranging Power Step (mW) & \multicolumn{2}{|l|}{0.25} & \\
\hline (3) & $\notin$ Timers & \multicolumn{2}{|l|}{ Default } & \\
\hline (2) & Contention Ranging Retries & \multicolumn{2}{|l|}{16} & \\
\hline \multirow[t]{2}{*}{ (2) Г } & + Mobility Parameters & \multicolumn{2}{|l|}{$(\ldots)$} & \\
\hline & - HARQ Parameters & \multicolumn{2}{|l|}{ (..) } & \\
\hline (2) & Maximum Retransmissions (numb. & \multicolumn{2}{|l|}{4} & \\
\hline (2) & Explicit ACK Delay (number of fra. & \multicolumn{2}{|l|}{1} & \\
\hline (?) & Number of Charnels (UL) & \multicolumn{2}{|l|}{8} & 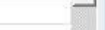 \\
\hline (3) & Number of Charnels (DL) & \multicolumn{2}{|l|}{16} & \\
\hline (3) & - Buffer Size Constant (K) & \multicolumn{2}{|l|}{20} & \\
\hline (2) & Buffer Aggregation Flag & \multicolumn{2}{|l|}{ Disabled } & \\
\hline (2) & Piggyback BW Request & \multicolumn{2}{|l|}{ Enabled } & \\
\hline (?) & CQICH Period & \multicolumn{2}{|l|}{3} & 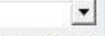 \\
\hline \multicolumn{2}{|c|}{ (3) } & \multirow[t]{2}{*}{ Filter } & \multicolumn{2}{|c|}{$\begin{array}{r}\Gamma \text { Advanced } \\
\Gamma \text { Applyto selected objects }\end{array}$} \\
\hline \multicolumn{2}{|c|}{$\Gamma$ Exact match } & & $\underline{\mathrm{OK}}$ & Cancel \\
\hline
\end{tabular}

Figure 5. Mobile (4-1)

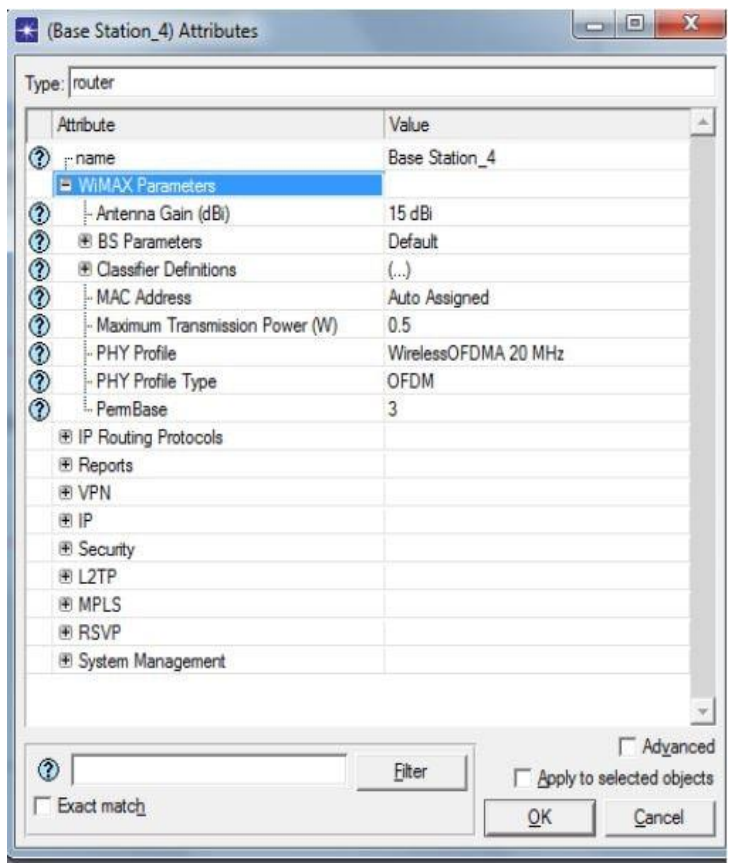

Figure 4. WiMAX BS

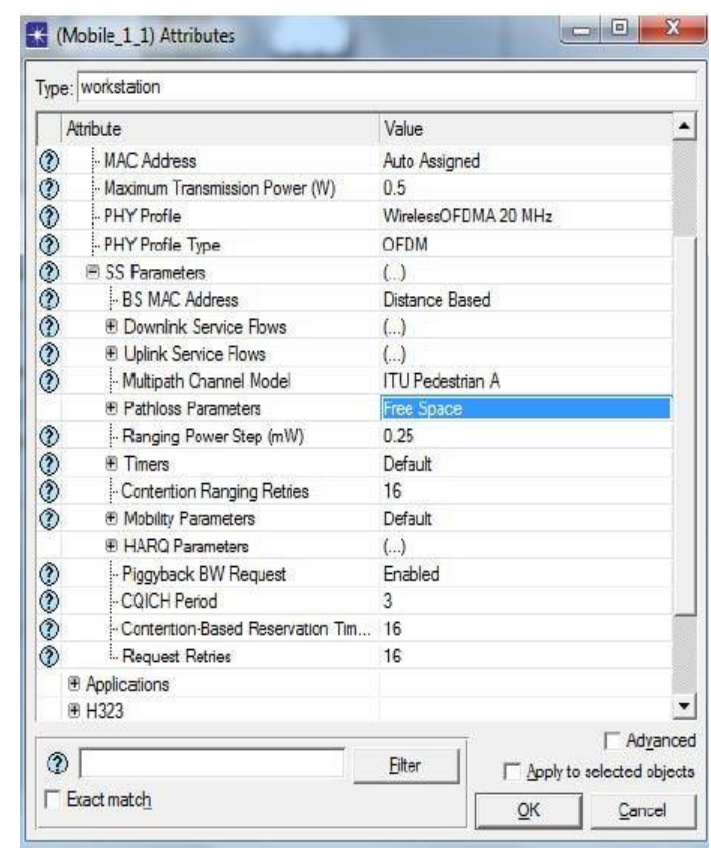

Figure 6. Mobile (1-1)

\section{RESULTS AND DISCUSSION}

The outputs of the different simulation run, which have been obtained, were statistically analyzed. The simulation results are average MOS for all networks, MOS for mobile (4-1), MOS for mobile (1-1), and throughput. Moreover, the quality of the VoIP call is measured through the result.

\subsection{OPNET simulation modeler}

OPNET can be defined as one of the research-oriented network simulation tools. It is also supplying a comprehensive development environment for simulation and modeling of the used wireless and wired networks. Users are enabled via OPNET Modeler to develop customized models and simulating many network situations, like Wi-MAX and WiFi [23]. The first simulation software related to commercial network performances has 
been provided via OPNET company, which offers one of the optimization tools of powerful network performances making developed network simulations [24]. Other products' development at OPNET besides Modeler was achieved; also, it includes kit of OPNET Development and WDM guru [25], [26].

The simulation was one of the testing procedures related to the developed prototype on platform duplicating real environment and offering the possibility to study, create and modify the performances related to design proposing to strengthen and weaken the expectations before model implementation a real environment [27], [28].

\subsection{Simulation result}

The results are obtained after implementing the IEEE802.16e network simulation by using OPNET Modeler. The simulation includes Throughput (packet/sec), mean opinion score (MOS). In Figure 7, the Scenario 1 consists of four cells, and each cell contain one mobile and one base station and the path used in the movement of the mobile for the base station is the star trajectory. In Figure 8 shows the average MOS value. The MOS value describes the perceived quality of receiving voice after being transmitted and compressed using codecs, the MOS value in our results when the network using star Trajectory and the BW 15 is recorded for mobile is higher than 3.5. Figure 9 shows the MOS for mobiles (1-1),(4-1) with used different parameters, With a note, in the case of using the multipath channel model (ITU pedestrian A) for mobile (1-1), the MOS is better and higher if use the multipath channel model (disable) for mobile (4-1). Moreover, in Figure 10, the throughput of mobile has a maximum rate of throughput of 1600 packets /sec when the network has star trajectory and the bandwidth (15 dB). In Figures (11),(12),(13) the network also has star trajectory but the Bandwidth $(-1 \mathrm{~dB})$. In Figure 11 the average MOS for all Network equal 3 . In Figure 12 also shows the MOS for mobiles (1-1),(4-1) with used different parameters, and using the multipath channel model (ITU pedestrian a) for mobile (1-1), and the multipath channel model (disable) for mobile (4-1), the MOS is better and higher if use the multipath channel model (disable) for mobile (4-1). In Figure 13 the throughput of mobile has a maximum rate of throughput of 1300 packets /sec when the network has star trajectory and the Bandwidth $(-1 \mathrm{~dB})$. However, when using the same scenario but with different bandwidths $(15 \mathrm{~dB},-1 \mathrm{~dB})$, we get different results, noting that throughput in the case of higher Bandwidth is better. According to result, it can observed that the MOS for Mobile (4-1) higher than 2.5. However, for mobile (1-1) equal to 1.5. Here shows the effect of the difference in the multipath channel model. Figure 9 shows that.

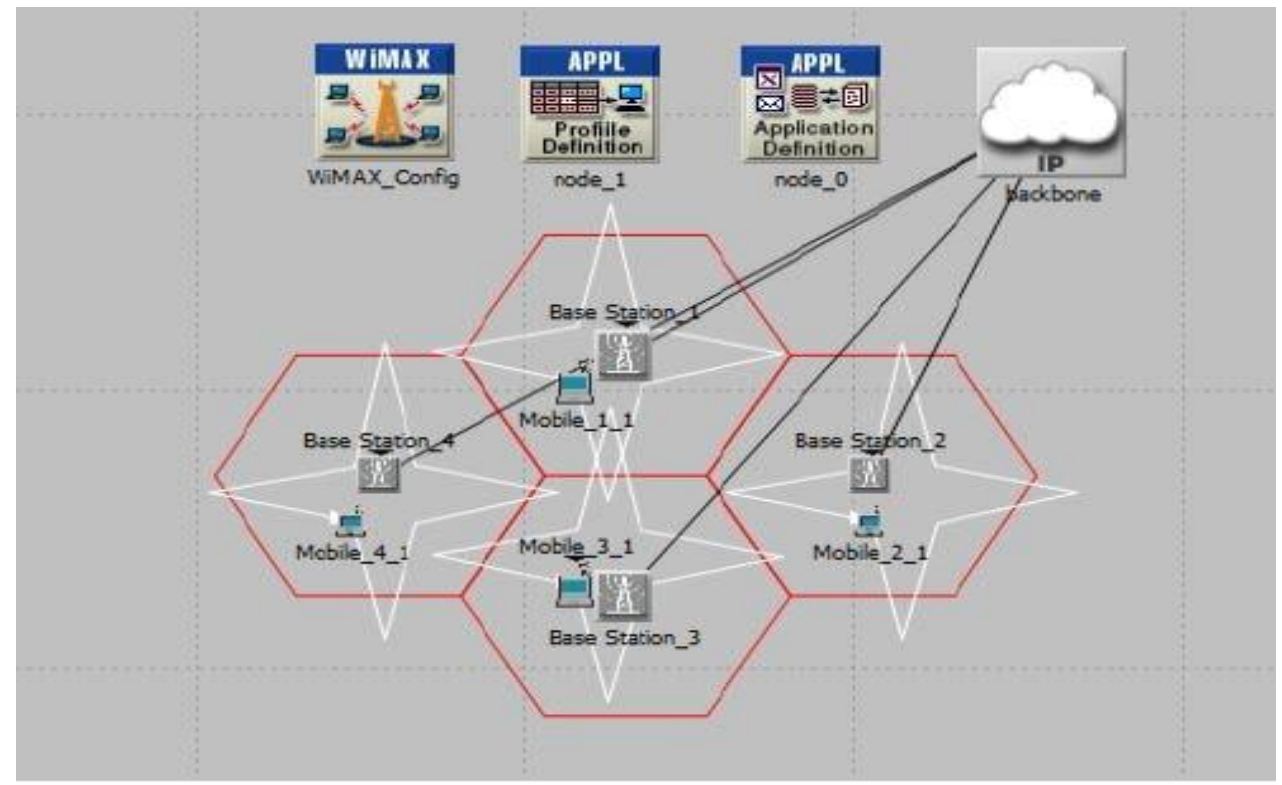

Figure 7. Scenario (1) WiMax network (star trajectory)

- $\quad$ For Mobile (4-1)

B. $\mathrm{W}=15$, path loss parameter $=$ free space

Multipath channel Model $=$ Disable

- $\quad$ For Mobile (1-1) 
B. $\mathrm{W}=15$, pathloss parameter $=$ free space

Multipath channel Model = ITU Pedestrian A

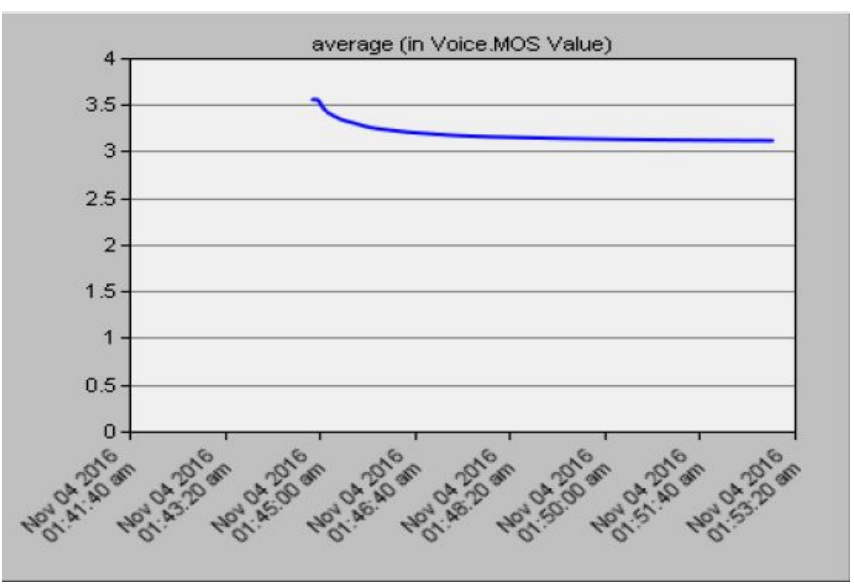

Figure 8. AverageMOS for all

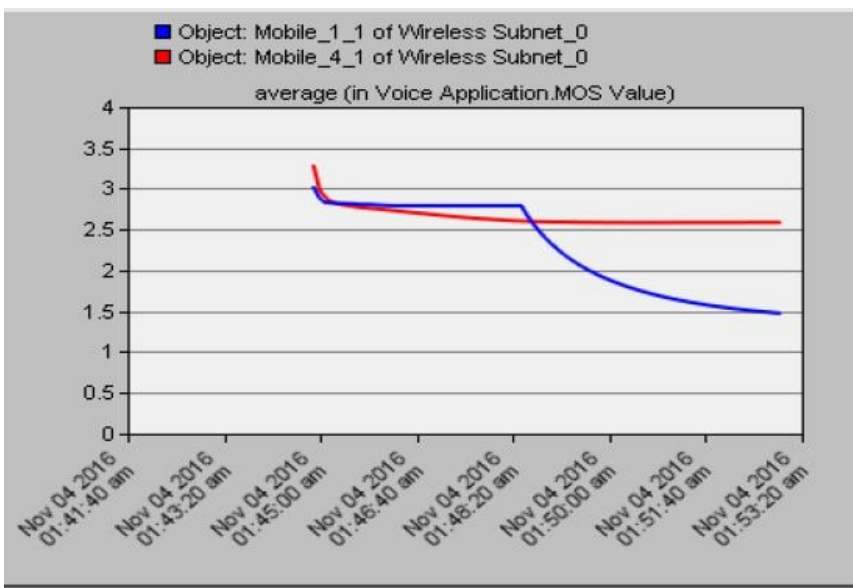

Figure 9. MOS

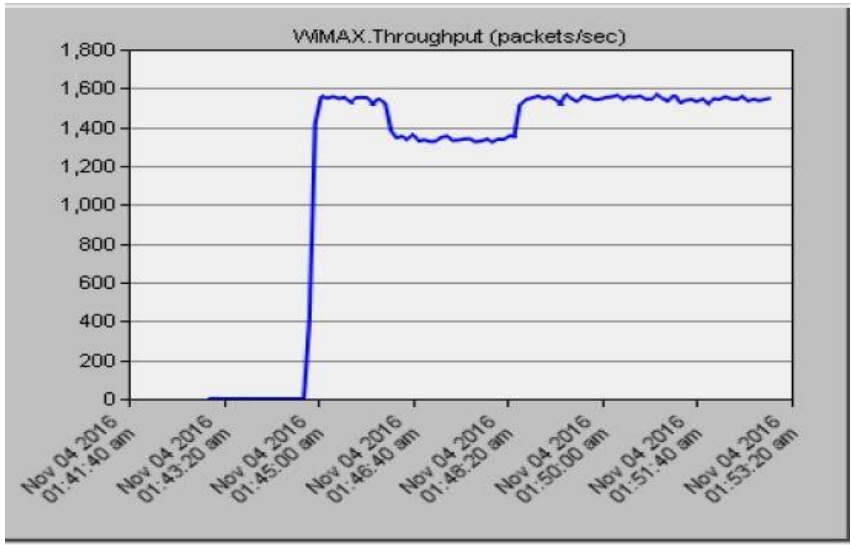

Figure 10. Throughp

In the same scenari, only the difference in Bandwidth $=-1 \mathrm{db}$ 
In this result, we can see the MOS for mobile (4-1) higher than 2.9. However, for mobile (1-1), less than 2. Here shows the effect of the difference in the multipath channel model

Figure 12 shows that,

- $\quad$ For mobile (4-1)

B. $W=-1 \mathrm{~dB}$, pathloss parameter $=$ free space

Multipath channel model $=$ Disable

- $\quad$ For mobile (1-1)

B. $\mathrm{W}=-1 \mathrm{~dB}$, pathloss parameter $=$ free space

Multipath channel model $=$ ITU Pedestrian A.

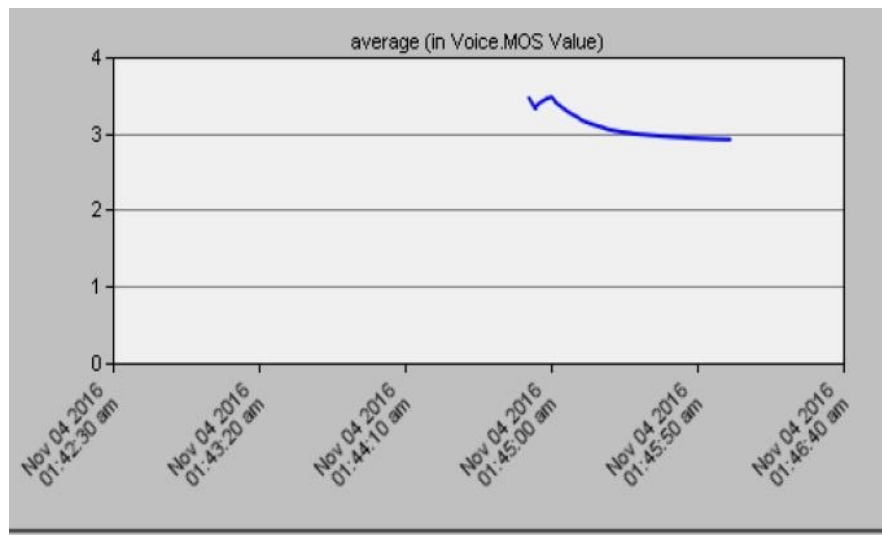

Figure 11. Average MOS for all network

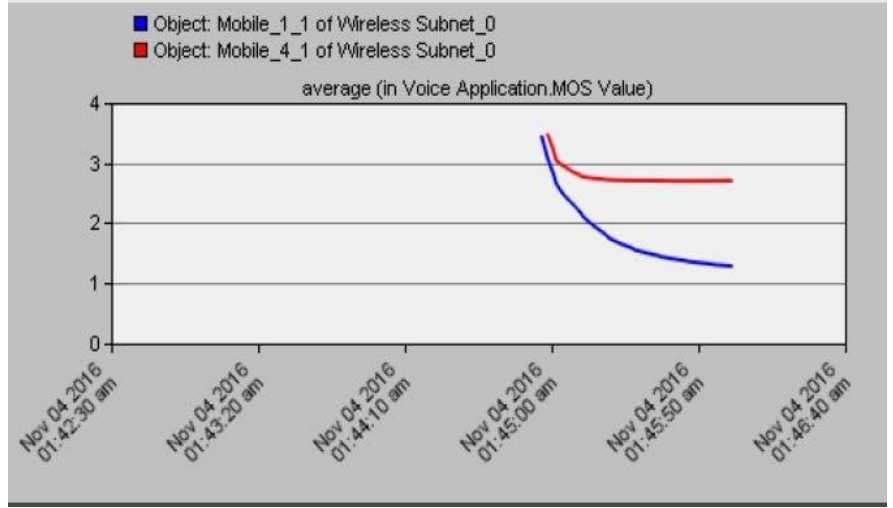

Figure 12. MOS

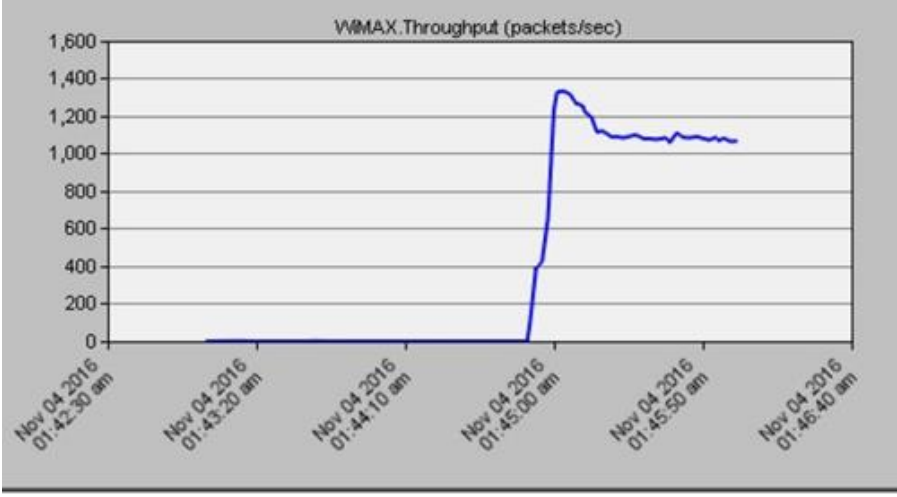

Figure 13. Throughput 


\section{CONCLUSION}

In this paper, extensive simulation study had conducted to evaluate the performance of WiMAX for supporting VoIP traffic. Important critical parameters such as Multipath channel model and bandwidth over the Star trajectory WiMAX network were analyzed. Simulation results show that when increase the bandwidth, the average MOS and the throughput was increased. Noting that the increase in bandwidth has a clearer effect on a throughput compared to MOS. The value of the throughput at $15 \mathrm{~dB}$ was approximately $1600 \mathrm{packet} / \mathrm{sec}$, and at $-1 \mathrm{~dB}$ was its value $1300 \mathrm{packet} / \mathrm{sec}$. On the other hand, the bandwidth was fixed at $(15 \mathrm{~dB},-1 \mathrm{~dB})$ with a change in the multipath channel model in two mobiles (1-1), (4-1). According to data, the multipath channel model of the disable types the value of the MOS was better than the ITU pedestrian A type. Future work includes adding other results, such as Traffic sent and received for mobiles, Jitter and End to end delay with the possibility of using other types of Multipath channel Model and clarifying the extent of their impact on the results. Performance was analyzed via OPNET program14.5. According to the results, the higher the BW, the better the results. In addition, the use of multipath channel model (disable) was better than using the model (ITU pedestrian A) the increase in bandwidth has a clearer effect on a throughput compared to MOS. The value of the throughput at $15 \mathrm{~dB}$ was approximately $1600 \mathrm{packet} / \mathrm{sec}$, and at $-1 \mathrm{~dB}$ was its value 1300 packet/se. According to data, the multipath channel model of the disable types the value of the MOS was better than the ITU pedestrian A type.

\section{REFERENCES}

[1] A Colbach, G. "The WiFi Networking Book: WLAN Standards: IEEE 802.11 Bgn, 802.11n, 802.11ac and 802.11ax" Independently Published 2019 https://books.google.iq/books?id=QO6xxgEACAAJ

[2] D. R. Mukaddim Pathan, Ramesh K. Sitaraman, "Advanced Content Delivery, Streaming, and Cloud Services," John Wiley \& Sons, Inc., Hoboken, New Jersey, 2014, doi:10.1002/9781118909690.

[3] S. Abdulmonem Saeed, "Performance Analysis of VoIP over Mobile WiMAX Networks," vol. 4, no. 6, pp. 2514-2518, 2016, doi: 10.1109/ICSGRC.2014.6908709.

[4] S. Islam, M. Rashid, and M. Tarique, "Performance Analysis of WiMax WiFi System under Different Codecs," Int. J. Comput. Appl., vol. 18, no. 6, pp. 13-19, 2011, doi: 10.5120/2290-2973.

[5] G. Rajaraman, K. Parthiban, M. Ramaswamy, "Dual Band Miniaturized Patch Antenna for WLAN, WIMAX Applications Using Spiral Meta component," IJSRSET, vol. 2, no. 2, pp. 1086-1089, Print ISSN: 2395-1990, Online ISSN: 2394-4099.

[6] R. Singh and S. Singh, "Evaluation of WIMAX 802.16 Technology Performance by Evaluating the Bit-Error Rate (BER) of OFDM Physical Layer under Different Modulation Schemes and Channel Conditions" International Journal of Innovative Research in Electrical, Electronics, Instrumentation and Control Engineering, vol. 4, no. 2 , February 2016, doi: 10.17148/IJIREEICE.2016.4212.

[7] M. H. Miraz, S. A. Molvi, M. A. Ganie, M. Ali, and A. R. H. Hussein, "Simulation and analysis of quality of service (QoS) parameters of voice over IP (VoIP) traffic through heterogeneous networks," International Journal of Advanced Computer Science and Applications(IJACSA), vol. 8, no. 7. 2017, doi: 10.14569/ijacsa.2017.080732.

[8] A. I. Alghannam and A. K. Alhafid, "Performance analysis of Unsolicited Grant Service (UGS) service class in WiMAX voip application," J. Eng. Sci. Technol., vol. 15, no. 3, pp. 1481-1491, 2020, Accessed: Nov. 21, 2020. [Online]. Available: http://jestec.taylors.edu.my/Vol 15 issue 3 June 2020/15_3_2.pdf

[9] A. A. Ali, S. Vassilaras, and K. Ntagkounakis, "A comparative study of bandwidth requirements of VoIP codecs over WiMAX access networks," in NGMAST 2009 - 3rd International Conference on Next Generation Mobile Applications, Services and Technologies, 2009, pp. 197-203, doi: 10.1109/NGMAST.2009.47.

[10] L. Nuaymi, "WiMAX: Technology for Broadband Wireless Access," John Wiley \& Sons, p. 310, 2007.

[11] I. Koffman and Vincentzio Roman.-I, "Broadband Wireless Access Solutions Based on OFDM Access in IEEE 802.16," IEEE communications magazine, vol. 40, no. 4, pp. 96-103.2002.

[12] L. Narvaez, J. Perez, C. Garcia, and V. Chi, "Designing 802.11 WLANs for VoIP and Data", IJCSNS International Journal of Computer Science and Network Security, vol. 7, no. 7, pp. 248-256, 2007.

[13] Rias M, Jeffrey G, Andrews, and Arunabha Ghosh, "Fundamentals of WiMAX: Understanding Broadband Wireless Networking," Pearson Education, 2007.

[14] T. C. Kwok, "Residential broadband internet services and applications requirements," IEEE Commun. Mag., vol. 35, no. 6, pp. 76-83, 1997, doi: 10.1109/35.587710.

[15] G. F. Ahmad Jubair, M. I. Hasan, and O. Ullah, "Performance Evaluation of IEEE 802 . 16e ( Mobile WiMAX ) in OFDM Physical Layer," 2009.

[16] M. Edwards, "IP telephony ready to explode into the corporate world,", pp. 96-97, 2001.

[17] P. P. Francis-Cobley and A. D. Coward, "Voice over IP versus voice over frame relay," International Journal of Network Management, vol. 14, no. 4. pp. 223-230, Jul. 2004, doi: 10.1002/nem.518.

[18] P. Chandrasekhar, M. Kumar, and M. Nathan, "Bandwidth-efficient voice activity detector," IET-UK International Conference on Information and Communication Technology in Electrical Sciences (ICTES 2007), pp. 533-538, 2007, doi: 10.1049/ic:20070669.

[19] S. Sengupta, M. Chatterjee, and S. Ganguly, "Improving quality of VoIP streams over WiMax," IEEE Trans. Comput., vol. 57, no. 2, pp. 145-156, 2008, doi: 10.1109/TC.2007.70804. 
[20] E. Halepovic, M. Ghaderi, and C. Williamson, "Multimedia application performance on a WiMAX network," in Multimedia Computing and Networking 2009, 2009, vol. 7253, p. 725309, doi: 10.1117/12.815557.

[21] I. Adhicandra, "Measuring Data and VoIP Traffic in WiMAX Networks," J. Telecommun., vol. 2, no. 1, pp. 1-6, Apr. 2010, Accessed: Nov. 21, 2020. [Online]. Available: http://arxiv.org/abs/1004.4583

[22] K. Pentikousis, E. Piri, J. Pinola, F. Fitzek, T. Nissilä, and I. Harjula, "Empirical evaluation of VoIP aggregation over a fixed WiMAX testbed," 4th International ICST Conference on Testbeds and Research Infrastructures for the Development of Networks \& Communities, 2008, doi: 10.4108/tridentcom.2008.3140.

[23] R. Prasad and F. J. Velez, WiMAX Networks: Techno-Economic Vision and Challenges, Netherlands: Springer, 2010, doi:10.1007/978-90-481-8752-2.

[24] S. A. S. Lafta, A. H. Ali, M. M. Kareem, Y. A. Hussein, and A. H. Ali, "Performance simulation of broadband multimedia wireless networks simulation based on OPNET," Indonesian Journal of Electrical Engineering and Computer Science, vol. 17, no. 1, pp. 1-9, 2020, doi: 10.11591/IJEECS.V17.I1.PP1-9.

[25] M. M. Kareem, M. Ismail, M. A. Altahrawi, N. Arsad, M. F. Mansor, and A. H. Ali, "Grid Based Clustering Technique in Wireless Sensor Network using Hierarchical Routing Protocol," ISTT 2018 - 2018 IEEE 4th Int. Symp. Telecommun. Technol., pp. 1-5, 2018, doi: 10.1109/ISTT.2018.8701720.

[26] M. I. Youssef, A. E. Emam, and M. Abd Elghany, "Image multiplexing using residue number system coding over MIMO-OFDM communication system," International Journal of Electrical and Computer Engineering, vol. 9, no. 6, pp. 4815-4825, 2019, doi: 10.11591/ijece.v9i6.pp4815-4825.

[27] D. A. Hussein Ali, "Analysis of Self-Homodyne and Delayed Self-Heterodyne Detections for Tunable Laser Source Linewidth Measurements," IOSR J. Eng., vol. 02, no. 10, pp. 01-06, 2012, doi: 10.9790/3021-021040106.

[28] A. J. Abid, F. M. Al-naima, and A. H. Ali, "Comprehensive Modeling of Photovoltaic Array based on Proteus Software,” Int. J. Appl. Eng. Res., vol. 13, no. 6, pp. 4440-4447, 2018, Accessed: Nov. 21, 2020.

\section{BIOGRAPHIES OF AUTHORS}
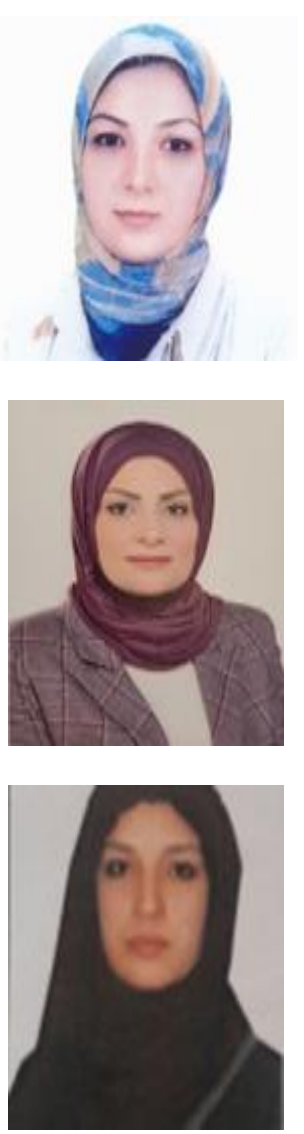

Noor Nateq Fadhil is an Assistant Lecturer in Computer Networks Department at the University of AL-Nahrain, Baghdad, Iraq. She received her BSc Eng. Degree in Communication Engineering from Diyala University and MSc in Telecommunications from University Politehnica of Bucharest, Romainia, in 2008, 2017 respectively. She has been a Lecturer in Fiber Optics and Wireless Communication since 2017. She is currently a Responsible on the Postgraduate students. Her research interests include the field of Wireless Communication, WiMax, Digital signal processing, Electronics, Optical Communication and digital library.

Suhad Qasim Naeem is an assistant Lecturer in information and communication Engineering Department at Al-Nahrain University, Baghdad, Iraq. She received her B.Sc. Eng. and M.Sc. Eng. in Electrical Engineering from University of Technology and Mustansiriyah University. In 1995, 2018, respectively. Her research interests include the field of digital communication, computer networking, digital electronics design, industrial informatics, renewable energy, FPGA applications, embedded system, artificial intelligence, intelligent control.

Azhar Hussein Neama is an Asst Lecturer in Information and Communication Engineering Department at the University Al Nahrain. She received her BSc.Eng. and MSc.Eng. degrees in Electrical Engineering from University Al Mustansiria, and University Baghdad respectively, in 2008 and 2018, respectively. Her research interests include the field of digital design, Optical Communication, electronics, visible light communication, and computer networks. 